\title{
Cysteine induces longitudinal bone growth in mice by upregulating IGF-I
}

\author{
PHIL-DONG MOON $^{1 *}$, MIN-HO KIM $^{2 *}$, HYUN-A OH $^{1}$, SUN-YOUNG NAM ${ }^{1}$, \\ NA-RA HAN ${ }^{1}$, HYUN-JA JEONG ${ }^{3}$ and HYUNG-MIN KIM ${ }^{1}$ \\ ${ }^{1}$ Department of Pharmacology, College of Korean Medicine, Kyung Hee University, Seoul 130-701; \\ ${ }^{2}$ Department of Computer Aided Mechanical Engineering, Sohae College, Gunsan, Jeonbuk, 573-717; \\ ${ }^{3}$ Biochip Research Center, Hoseo University, Asan, Chungnam 336-795, Republic of Korea
}

Received October 31, 2014; Accepted June 16, 2015

DOI: $10.3892 /$ ijmm.2015.2257

\begin{abstract}
Cysteine (Cys) is known to exert various effects, such as antioxidant, antipancreatitic and antidiabetic effects. However, the effects of Cys on longitudinal bone growth have not been elucidate to date. Thus, the aim of the present study was to evaluate the effects of Cys on bone growth. Growth-plate thickness and bone parameters, such as bone volume/tissue volume (BV/TV), trabecular thickness (Tb.Th), trabecular number (Tb.N), connectivity density (Conn.D) and total porosity were analyzed by means of micro-computed tomography $(\mu \mathrm{CT})$. The levels of serum insulin-like growth factor-I (IGF-I) were measured by enzyme-linked immunosorbent assay (ELISA). Hepatic IGF-I mRNA expression was analyzed by quantitative polymerase chain reaction (qPCR). The phosphorylation of Janus kinase 2 (JAK2) and signal transducer and activator of transcription 5 (STAT5) was investigated by western blot analysis. Our results revealed that Cys increased IGF-I mRNA expression in HepG2 cells. The thickness of the growth plates was increased following treatment with Cys. Moreover, BV/TV, Tb.Th, TbN, Conn.D and total porosity were improved following treatment with Cys. Hepatic IGF-I mRNA expression and serum IGF-I levels were increased by Cys. The levels of phosphorylated JAK2 and STAT5 were elevated by Cys. The findings of our study indicate that Cys increases the thickness of growth plates through the upregulation of IGF-I, which results from the phosphoryla-
\end{abstract}

Correspondence to: Professor Hyun-Ja Jeong, Biochip Research Center, Hoseo University, 165 Sechul-ri, Baebang-myun, Asan, Chungnam 336-795, Republic of Korea

E-mail: hjjeong@hoseo.edu

Professor Hyung-Min Kim, Department of Pharmacology, College of Korean Medicine, Kyung Hee University, 1 Hoegi-dong, Dongdaemun-gu, Seoul 130-701, Republic of Korea

E-mail: hmkim@khu.ac.kr

*Contributed equally

Key words: cysteine, growth plate, bone parameters, insulin-like growth factor-I, Janus kinase 2, signal transducer and activator of transcription 5 tion of JAK2-STAT5. Thus, our data suggest that Cys may have potential for use as a growth-promoting agent.

\section{Introduction}

Longitudinal bone growth is a results of the proliferation, hypertrophy and matrix production of cartilage cells in growth plates (1). The growth plate is a relatively thin layer of cartilage which is found in growing long bones during longitudinal skeleton growth $(2,3)$. The growth of the long bone at the growth plate is regulated by an endocrine signaling systems that involves glucocorticoids, growth hormone $(\mathrm{GH})$ and insulin-like growth factor-I (IGF-I) (4). If a child is afflicted by poor nutrition, the levels of thyroid hormones and IGF-I decline, and during puberty, malnutrition also causes the downregulation of sex steroids. These endocrine changes decrease the elongation of bones (4). In order to reproduce this malnutrition, mice are fed a low-protein diet. Protein-energy malnutrition (PEM) is an important form of undernourishment and is a condition caused by an inequality between food intake (protein and energy) and the amount that the body requires for optimal growth and function (5).

$\mathrm{GH}$ is a pivotal factor in development and growth (6). $\mathrm{GH}$ begins to exert its effects when it binds to its receptor, $\mathrm{GH}$ receptor (GHR), which is present on the cell surface (7). After GH binds to GHR, several signaling cascades are activated, including the Janus kinase 2 (JAK2)-signal transducer and activator of transcription (STAT) 5 signaling pathway, and the phospholipase $\mathrm{C}$ /protein kinase $\mathrm{C} / \mathrm{Ca}^{2+}$ pathway $(8,9)$. The most well characterized signaling cascade is the JAK2-STAT5 pathway, which mediates the effects of GH on gene transcription in the liver $(10,11)$. This pathway is responsible for the transcription of the GH target gene IGF-I (12). IGF-I is considered essential for longitudinal bone growth and plays an important role in cell growth and survival. In general, the majority of plasma IGF-I is produced in the liver (13-15).

Cysteine (Cys) (Fig. 1) is a semi-essential amino acid that is known to exert antioxidant, antipancreatitic and antidiabetic effects (16-18). However, the effects of Cys on bone growth have not been elucidate to date. Thus, in this study, we aimed to investigate the effects of Cys on longitudinal bone growth and to elucidate the underlying mechansims. 


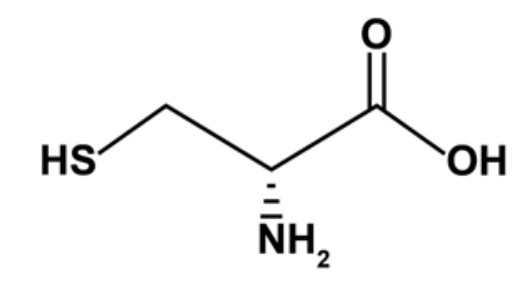

Figure 1. Chemical structure of cysteine (Cys).

\section{Materials and methods}

Reagents. Cys, avidin-peroxidase and bovine serum albumin were purchased from Sigma Chemical Co. (St. Louis, MO, USA). Anti-mouse IGF-I antibody (Cat. no. MAB791), biotinylated anti-mouse IGF-I antibody (Cat. no. BAF791) and recombinant mouse IGF-I (Cat. no. 791-MG-050) were purchased from R\&D Systems (Minneapolis, MN, USA). The phosphorylated (p-)JAK2 (Cat. no. 44-426G) and STAT5 (Cat. no. 71-6900) antibodies were purchased from Invitrogen Life Technologies (Camarillo, CA, USA). JAK2 (Cat. no. sc-294) and STAT5 (Cat. no. sc-836) antibodies were purchased from Santa Cruz Biotechnology (Santa Cruz, CA, USA).

Cell culture and treatment. The human hepatocellular carcinoma cell line, HepG2 (from the Korean Cell Line Bank), was grown in DMEM (Gibco, Grand Island, NY, USA) containing penicillin (100 units $/ \mathrm{ml}$; Gibco), streptomycin $(100 \mu \mathrm{g} / \mathrm{ml}$; Gibco) and 10\% fetal bovine serum (HyClone, Logan, UT, USA) at $37^{\circ} \mathrm{C}$ in an incubator with $95 \%$ humidified air $/ 5 \% \mathrm{CO}_{2}$. The cells were treated with $0.5-50 \mu \mathrm{g} / \mathrm{ml}$ of Cys for $12 \mathrm{~h}$. The control group represented cells treated with the vehicle (distilled water).

Animals and diet. Male Institute of Cancer Research (ICR) mice (4 weeks old) and food were purchased from Dae-Han Experimental Animal Center (Eumsung, Korea). The mice were allowed to acclimatize for 7 days and were then randomly assigned to an adequate-protein diet group [control (CON) group, 20\% protein] or a low-protein diet group (PEM group, $4 \%$ protein), as previously described (19). The protein source used was casein. Aside from the protein content, the 2 diets were identical and isocaloric (Table I). After 2 weeks, the mice were divided into 3 groups ( 5 mice per group) as follows: i) the $\mathrm{CON}$ group: mice were fed an adequate-protein diet + distilled water (DW); ii) the PEM group: mice were fed a low-protein diet + DW; and iii) the Cys group: mice were fed a low-protein diet and administered Cys. The mice were fed an adequate-protein diet or a low-protein diet and were administered orally with DW or Cys $(50 \mathrm{mg} / \mathrm{kg})$ using a stomach sonde twice a week for 12 weeks, as previously described in the study by Farombi et al (20). It is widely accepted that bone growth is associated with a gain in body weight. Thus, the mice were weighed at the end of the experiment. The mice were housed in a laminar air-flow room, with a constant temperature of $22 \pm 1^{\circ} \mathrm{C}$ and a relative humidity of $55 \pm 1 \%$, throughout the study. All epxeriments were conducted in accordance with internationally accepted principles for laboratory animal use and care, as found in US guidelines (NIH publication no. 85-23, revised in 1985).
Table I. Composition of experimental diets.

\begin{tabular}{lcc}
\hline Ingredients & $\begin{array}{c}\text { Standard chow diet } \\
(\mathrm{g} / \mathrm{kg} \text { diet })\end{array}$ & $\begin{array}{c}\text { PEM diet } \\
(\mathrm{g} / \mathrm{kg} \text { diet })\end{array}$ \\
\hline Casein $(>85 \%$ protein $)$ & 200 & 40 \\
Sucrose & 100 & 100 \\
Fiber & 10 & 10 \\
Corn oil & 80 & 80 \\
Mineral mixture & 40 & 40 \\
Vitamin mixture & 10 & 10 \\
L-methionine & 1.5 & 1.5 \\
Choline bitartrate & 2.5 & 2.5 \\
Cornstarch & 556.5 & 716.5 \\
\hline
\end{tabular}

Isocaloric diets providing $1716.3 \mathrm{~kJ} / 100 \mathrm{~g}$. Mineral and vitamin mixtures were prepared according to the 1993 recommendations of the American Institute of Nutrition for adult mice (19). PEM, protein-energy malnutrition.

Enzyme-linked immunosorbent assay (ELISA). The levels of IGF-I were measured by a modified ELISA, as previously described (21-24). A sandwich ELISA for IGF-I was carried out in a duplicate in a 96-well ELISA plate. The plate was coated with anti-mouse IGF-I antibody and incubated overnight at $4^{\circ} \mathrm{C}$. The plate was washed in PBS containing $0.05 \%$ Tween- 20 (Sigma) and blocked with PBS containing $1 \%$ bovine serum albumin, $5 \%$ sucrose and $0.05 \% \mathrm{NaN}_{3}$ for $1 \mathrm{~h}$. After additional washes, the culture supernatant and IGF-I standards were added and incubated at room temperature for $2 \mathrm{~h}$. After $2 \mathrm{~h}$ incubation at room temperature, the plate was washed and biotinylated anti-mouse IGF-I was then added and again incubated at room temperature for $2 \mathrm{~h}$. After washing the wells, avidin-peroxidase was added and the plate was incubated for $30 \mathrm{~min}$ at $37^{\circ} \mathrm{C}$. The wells were again washed and TMB substrate (Pharmingen, San Diego, CA, USA) was added. Color development was measured at $405 \mathrm{~nm}$ using an automated microplate ELISA reader. A standard curve was run on the plate using recombinant mouse IGF-I in serial dilutions.

Quantitative polymerase chain reaction ( $q P C R)$. $\mathrm{qPCR}$ was performed using SYBR-Green Master Mix, and the detection of mRNA was carried out using an ABI StepOne real-time PCR system (Applied Biosystems, Foster City, CA, USA), as previously described (25-27). PCR was performed with the following primers: human IGF-I forward, 5'-TGC CCA AGA CCC AGA AGT-3' and reverse, 5'-CTC CTG TCC CCT CCT TCT GTT-3'; human GAPDH forward, 5'-TCG ACA GTC AGC CGC ATC TTC TTT-3' and reverse, 5'-ACC AAA TCC GTT GAC TCC GAC CTT-3'; mouse IGF-I forward, 5'-CCG GAC CAG AGA CCC TTT G-3' and reverse, 5'-CCT GTG GGC TTG TTG AAG TAA AA-3'; and mouse GAPDH forward, 5'-GGC AAA TTC AAC GGC ACA-3' and reverse, 5'-GTT AGT GGG GTC TCG CTC CTG-3'. Typical profile times used were an initial step, $95^{\circ} \mathrm{C}$ for 10 min followed by a second step at $95^{\circ} \mathrm{C}$ for $15 \mathrm{sec}$ and $60^{\circ} \mathrm{C}$ for $30 \mathrm{sec}$ for 40 cycles with a melting curve analysis. The level of target mRNA was normalized to the level of GAPDH and compared with the control. Data were analyzed using the $\Delta \Delta \mathrm{CT}$ method. 
Western blot analysis. The supernatants of the homogenized liver tissues were prepared in a sample buffer [62.5 $\mathrm{mM}$ Tris hydrochloride (Tris- $\mathrm{HCl}$ ), $\mathrm{pH} 6.8,2 \%$ sodium dodecyl sulphate (SDS), $20 \%$ glycerol and $10 \%$ 2-mercaptoethanol], as previously described (28-30). The samples were heated at $95^{\circ} \mathrm{C}$ for $5 \mathrm{~min}$ and briefly cooled on ice. Following centrifugation at $15,000 \mathrm{x} \mathrm{g}$ for $5 \mathrm{~min}$, the proteins in the lysates were then separated by $10 \%$ SDS-polyacrylamide gel electrophoresis and transferred onto a nitrocellulose membrane. The membrane was blocked with $5 \%$ skim milk in PBS-tween-20 for $1 \mathrm{~h}$ at room temperature and then incubated with primary (p-JAK2, 1:500 dilution; p-STAT5, 1:500 dilution; JAK2, 1:1,000 dilution; STAT5, 1:1,000 dilution) and secondary (mouse anti-rabbit IgG-HRP, 1:5,000 dilution, Santa Cruz Biotechnology, Santa Cruz, CA, USA) antibodies. Finally, the protein bands were visualized by an enhanced chemiluminesence solution purchased from Amersham Co. (Newark, NJ, USA) following the manufacturer's instructions.

Micro-computed tomography $(\mu C T)$. The 2D and $3 \mathrm{D}$ information on bone geometry was attained by high-resolution $\mu \mathrm{CT}$, as previously described $(31,32)$. The mice were sacrificed; the femora and tibiae were dissected, cleaned of soft tissue, and fixed in $4 \%$ formaldehyde before storage. The source of the open tube type and the minimum focal spot size was $8 \mu \mathrm{m}$. Reconstruction was carried out using a modified Feldkamp algorithm using SkyScan NRecon software (SkyScan, Kontich, Belgium). The x-ray source was set at $75 \mathrm{kV}$ and $100 \mathrm{~mA}$. Four hundred projections were acquired over an angle of $180^{\circ}$. The image slices were reconstructed using cone-beam reconstruction software based on the Feldkamp algorithm (Dataviewer; SkyScan). The trabecular bone was extracted by drawing ellipsoid contours with CT analyzer software. Trabecular bone volume (BV/TV; percentage) and trabecular number (Tb.N) of femur epiphysis and proximal tibial metaphysis were calculated by the mean intercept length method. Trabecular thickness (Tb.Th; mm) was calculated according to the study of Ngueguim et al (31). 3D parameters were based on analysis of a Marching cubes-type model with a rendered surface. To analyze 3D parameters in tibias, whole bone was scanned, and 600 slices of $8 \mu \mathrm{m}$ in thickness were placed through the former area. Bone mineral density (BMD), bone volume/tissue volume (BV/TV), trabecular thickness (Tb.Th), trabecular number (Tb.N), connectivity density (Conn.D), and total porosity were recorded. The thickness of excised bone growth plate was determined using SkyScan 1076 software (SkyScan) as described in a previously published protocol (32).

Statistical analysis. Statistical analysis was performed using SPSS software (version 14.0; SPSS Inc., Chicago, IL, USA). All results are expressed as the means \pm SEM. The statistical evaluation of the results was performed by an independent t-test and an ANOVA with Tukey's post hoc test. $\mathrm{P}$ values $<0.05$ were considered to indicate statistically significant differences.

\section{Results}

Effect of Cys on IGF-I mRNA in HepG2 cells. IGF-I plays an important role in linear bone growth (33). Thus, to determine whether Cys increases IGF-I mRNA expression in the liver, we used a hepatocyte cell line, HepG2. When we treated the

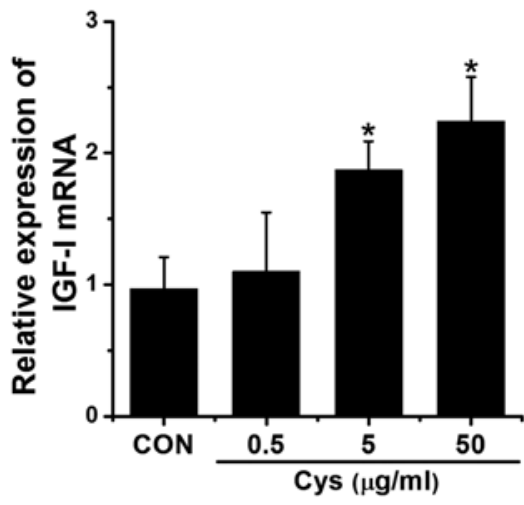

Figure 2. Effect of cysteine (Cys) on insulin-like growth factor-I (IGF-I) mRNA expression in HepG2 cells. HepG2 cells $\left(5 \times 10^{5}\right)$ were treated with $0.5-50 \mu \mathrm{g} / \mathrm{ml}$ of Cys for $12 \mathrm{~h}$. Data represent the means \pm SEM of 3 independent experiments. ${ }^{*} \mathrm{P}<0.05$ denotes a significant difference compared to the control (CON, vehicle-treated cells).

HepG2 cells with Cys $(0.5-50 \mathrm{mg} / \mathrm{ml})$, IGF-I mRNA expression was elevated in a dose-dependent manner (Fig. 2). Treatment with $50 \mathrm{mg} / \mathrm{ml}$ of Cys had the most prominent effect, and thus we evaluated the effects of treatment with $50 \mathrm{mg} / \mathrm{kg}$ of Cys in the next set of experiments, i.e., in vivo mouse models.

Effect of Cys on growth plates in mice. The thickness of the growth plate in the proximal tibia was assessed (Fig. 3A), and we also investigated linear bone growth using $\mu \mathrm{CT}$. The thickness of the growth plates in the proximal tibias

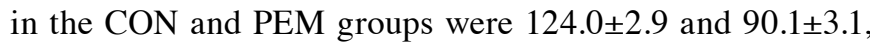
respectively; the growth-plate thickness in the Cys group was $117.0 \pm 4.3(\mathrm{P}<0.05$; Fig. 3B). Thus, it is clear that Cys significantly increased linear bone growth, compared to the PEM group. In addition, treatment with Cys significantly increased the body weight of the mice compared to the PEM group.

Effect of Cys on trabecular bone parameters. We used $\mu \mathrm{CT}$ measurements to determine whether Cys improves longitudinal bone growth. The administration of Cys increased BMD (Fig. 4A). The results of the $3 \mathrm{D} \mu \mathrm{CT}$ reconstruction of the trabecular bone images, which were converted into parameters representing trabecular connectivity, demonstrated that the BV/TV, Tb.Th, Tb.N and Conn.D in the tibia were increased by treatment with Cys, and that total porosity was decreased (Fig. 4B-F).

Effect of Cys on the regulation of IGF-I. To investigate whether Cys increase serum IGF-I levels, we measured the IGF-I levels by ELISA. The serum IGF-I levels were significantly increased by Cys, compared to those of the PEM group ( $\mathrm{P}<0.05$; Fig. $5 \mathrm{~A}$ ). We then examined the mRNA expression of IGF-I in the liver, as the majority of plasma IGF-I is produced in the liver. The mRNA expression of IGF-I in the liver was shown to be significantly upregulated in the mice administered Cys, compared to the mice in the PEM group ( $\mathrm{P}<0.05$; Fig. 5B).

Effect of Cys on levels of p-JAK2 and p-STAT5. To examine whether the linear bone growth caused by Cys is regulated by JAK2-STAT5 phosphorylation, we performed western blot analysis. As depicted in Fig. 6, the levels of p-JAK2 and 

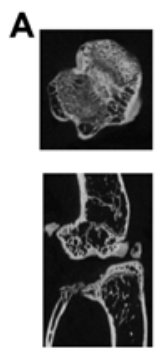

CON
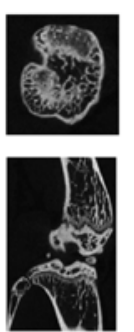

PEM
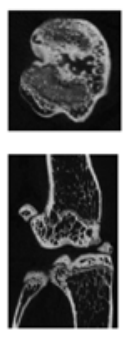

Cys
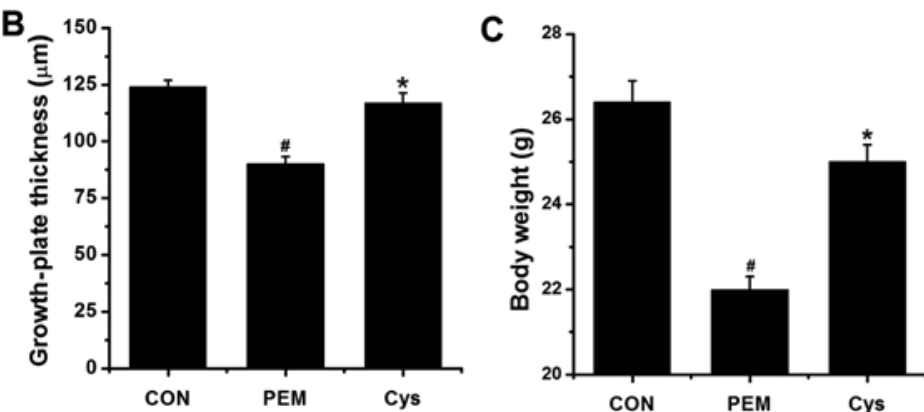

Figure 3. Effect of cysteine (Cys) on the thickness of the tibial growth plate. (A) The thickness of excised bone from the growth plate was measured at 5 points using the SkyScan 1076. (B) Growth-plate thickness in the mice in each group. (C) Body weight of the mice in each group.Data represent the means \pm SEM of 3 independent experiments. ${ }^{~} \mathrm{P}<0.05$ denotes a significant difference compared to the control (CON). ${ }^{*} \mathrm{P}<0.05$ denotes a significant difference compared to the protein-energy malnutrition (PEM) group. CON, group administered adequate-protein diet + distilled water (DW); PEM, group administered low-protein diet + DW; Cys, group administered low-protein diet + Cys.
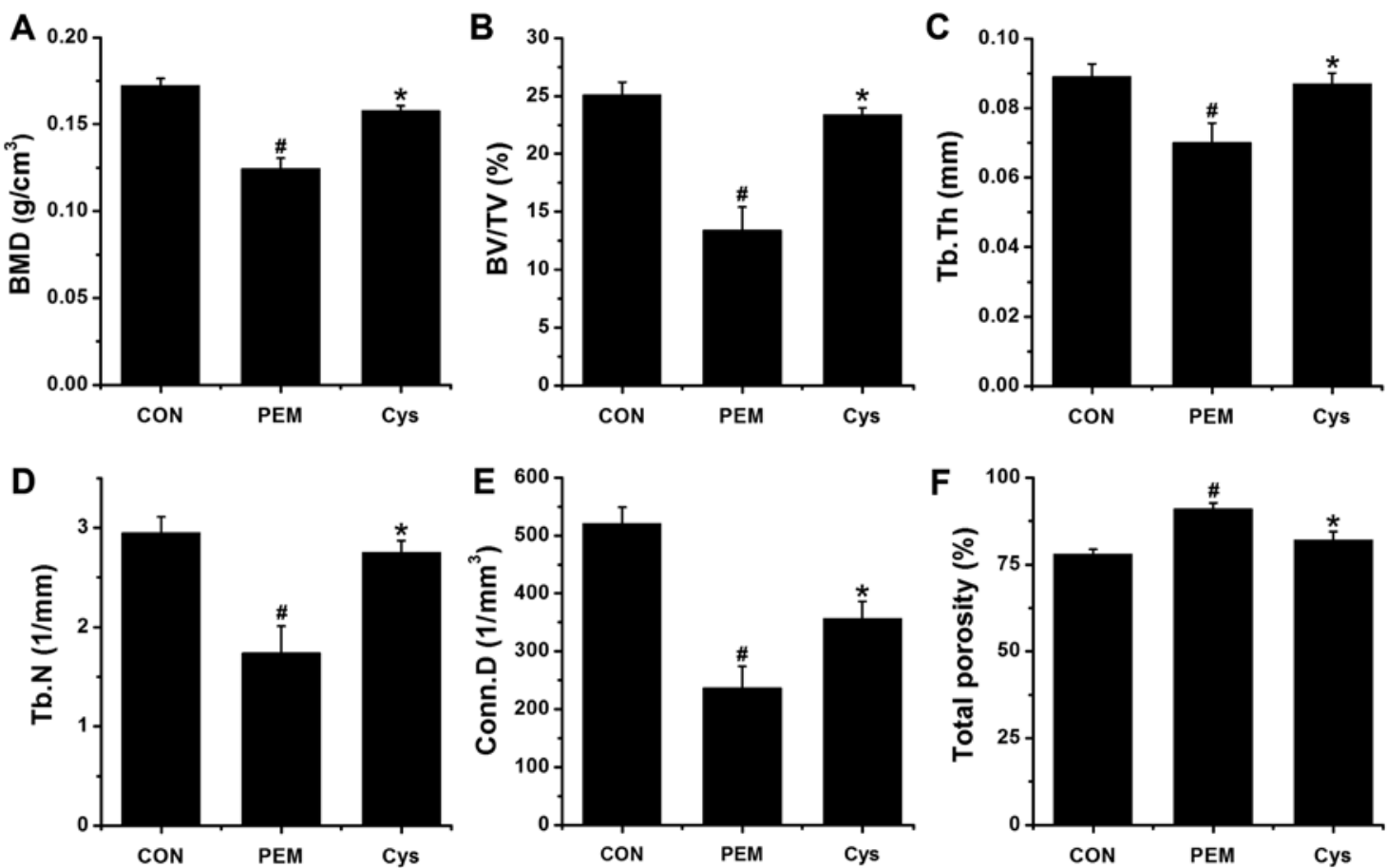

Figure 4. Effect of cysteine (Cys) on trabecular bone parameters. Bone mineral density (BMD) and trabecular parameters of excised bone at the tibia were measured. (A) BMD levels were measured using 2D micro-computed tomography ( $\mu \mathrm{CT}$ ). (B-F) Quantified parameters (BV/TV, Tb.Th, Tb.N, Con.D and total porosity) of proximal tibia were measured using $3 \mathrm{D} \mu \mathrm{CT}$. Data represent the means $\pm \mathrm{SEM}$ of 3 independent experiments. " $\mathrm{P}<0.05$ denotes a significan difference compared to the CON. "P $<0.05$ denotes a significant difference compared to the protein-energy malnutrition (PEM) group. BV/TV, bone volume/tissue volume; Tb.Th, trabecular thickness; Tb.N, trabecular number; Conn.D, connectivity density; CON, group administered adequate-protein diet + distilled water (DW); PEM, group administered low-protein diet + DW; Cys, group administered low-protein diet + Cys.
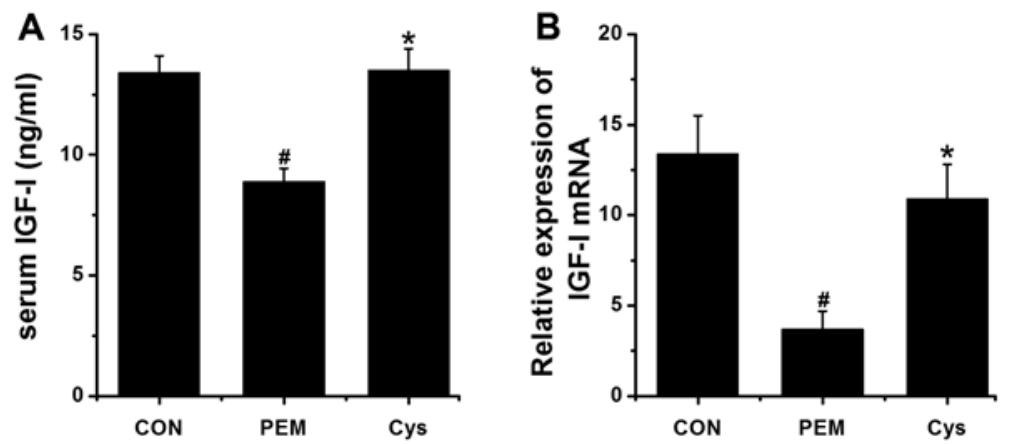

Figure 5. Effect of cysteine (Cys) on insulin-like growth factor I (IGF-I) levels. (A) Serum IGF-I levels were measured by ELISA. (B) The mRNA expression of IGF-I was measured by qPCR. Data represent the means \pm SEM of 3 independent experiments. ${ }^{\#} \mathrm{P}<0.05$ denotes a significant difference compared to the CON . ${ }^{*} \mathrm{P}<0.05$ denotes a significant difference compared to the protein-energy malnutrition (PEM) group. CON, group administered adequate-protein diet + distilled water (DW); PEM, group administered low-protein diet + DW; Cys, group administered low-protein diet + Cys. 


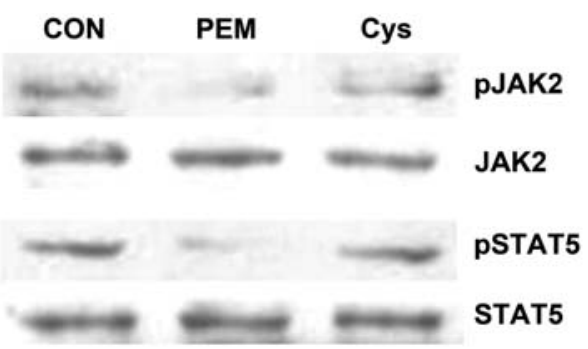

Figure 6. Effect of cysteine (Cys) on the phosphorylation of Janus kinase 2 (JAK2) and signal transducer and activator of transcription 5 (STAT5). Liver tissues of each mouse were homogenized and analyzed for the expression of phosphorylated (p-)JAK2, JAK2, p-STAT5 and STAT5. CON, group administered adequate-protein diet + distilled water (DW); PEM, group administered low-protein diet + DW; Cys, group administered low-protein diet + Cys. PEM, protein-energy malnutrition.

p-STAT5 in the liver were decreased due to malnutrition. However, the decrease in the level sof p-JAK2 and p-STAT5 was reversed by treatment with Cys (Fig. 6).

\section{Discussion}

In the present study, we demonstrated that Cys increased the mRNA expression of IGF-I, increased the thickness of growth plates, and increased the BV/TV, Tb.Th, Tb.N and Conn.D; Cys decreased total porosity. In addition, Cys increased the serum IGF-I levels through JAK2-STAT5 phosphorylation.

In general, endochondral cell proliferation in the growth plate results in bone growth. Thus, growth-plate thickness is a direct indicator of linear bone growth (34). Our results demonstrated that Cys increased growth-plate thickness (Fig. 3). From this result, it is suggested that Cys may prove to be helpful to children whose growth is retarded.

Cys is a sulfur-containing amino acid (35). A deficiency of sulfur amino acid has been shown to decrease neonatal pig growth (36). McLean et al (37) reported that Cys restored growth which was inhibited by paracetamol. In addition, Cys has been shown to induce the growth of human peritoneal mesothelial cells (38). In the present study, the sulfur-containing amino acid, Cys, increased growth-plate thickness in mice fed a PEM diet (Fig. 3). Thus, we can presume that the effect of Cys on bone growth, in part, is due to sulfur.

Baines et al (39) reported that subjects with low BMD had a significantly lower plasma Cys concentration, suggesting that there is an association between Cys and bone mass. In the present study, we demonstrated that Cys elevated tibial BMD, in ways consistent with a previous report (39). Furthermore, we noted that Cys improved bone parameters (it increased BV/TV, Tb.Th, Tb.N, Conn.D and decreased total porosity; Fig. 4B-F). Thus, Cys may have the potential to improve not only growth retardation, but may also alleviate osteoporosis.

Growth retardation is a major concern in children with chronic inflammatory diseases, uncontrolled juvenile idiopathic arthritis and chronic kidney disease (40-42). Thus, many children are administered the anti-inflammatory drug, dexamethasone. However, Baron et al (43) reported that dexamethasone acts locally to suppress linear bone growth in rabbits. It is fortunate that IGF-1 possesses anti-apoptotic properties and may, therefore, have the ability to prevent dexamethasone-induced chondrocyte apoptosis. Chrysis et al (44) demonstrated that IGF-I prevented dexamethasone-induced apoptosis, as well as the suppression of chondrocyte proliferation. In the present study, Cys elevated the level of serum IGF-I (Fig. 5). Thus, we can speculate that Cys partially counteracts the dexamethasone-induced growth retardation through the upregulation of IGF-I.

$\mathrm{GH}$ has long been known to stimulate linear growth and regulate metabolism. The binding of $\mathrm{GH}$ to GHR promotes the phosphorylation of JAK2 and STAT5 $(45,46)$. GH-induced IGF-I gene transcription is mediated by STAT5B (12). In our study, we noted that Cys increased the levels of p-JAK2 and p-STAT5 (Fig. 6). Thus, our findings suggest that Cys promotes linear bone growth through the phosphorylation of JAK2-STAT5.

In conclusion, in the present study, we demonsrated that Cys increased growth-plate thickness and improved bone parameters in mice. In addition, Cys upregulated the IGF-I levels through the phosphorylation of JAK2-STAT5. Overall, these results suggest that Cys may prove to be helpful in children whose growth is retarded, as it induces longitudinal bone growth through the upregulation of IGF-I.

\section{Acknowledgements}

This study was supported by the Ministry of Trade, Industry and energy (MOTIE), KOREA, through the Education Support program for Creative and Industrial Convergence.

\section{References}

1. Brito I, Gil-Peña H, Molinos I, Loredo V, Henriques-Coelho T, Caldas-Afonso A and Santos F: Growth cartilage expression of growth hormone/insulin-like growth factor I axis in spontaneous and growth hormone induced catch-up growth. Growth Horm IGF Res 22: 129-133, 2012.

2. Abad V, Meyers JL, Weise M, Gafni RI, Barnes KM, Nilsson O, Bacher JD and Baron J: The role of the resting zone in growth plate chondrogenesis. Endocrinology 143: 1851-1857, 2002.

3. Loqman MY, Bush PG, Farquharson C and Hall AC: Suppression of mammalian bone growth by membrane transport inhibitors. J Cell Biochem 114: 658-668, 2013.

4. Lui JC and Baron J: Effects of glucocorticoids on the growth plate. Endocr Dev 20: 187-193, 2011.

5. Fock RA, Rogero MM, Vinolo MA, Curi R, Borges MC and Borelli P: Effects of protein-energy malnutrition on NF-kappaB signalling in murine peritoneal macrophages. Inflammation 33: 101-109, 2010.

6. de Vos AM, Ultsch M and Kossiakoff AA: Human growth hormone and extracellular domain of its receptor: crystal structure of the complex. Science 255: 306-312, 1992.

7. Brooks AJ and Waters MJ: The growth hormone receptor: mechanism of activation and clinical implications. Nat Rev Endocrinol 6: 515-525, 2010.

8. Le Roith D, Bondy C, Yakar S, Liu JL and Butler A: The somatomedin hypothesis: 2001. Endocr Rev 22: 53-74, 2001.

9. Gevers EF, Hannah MJ, Waters MJ and Robinson IC: Regulation of rapid signal transducer and activator of transcription-5 phosphorylation in the resting cells of the growth plate and in the liver by growth hormone and feeding. Endocrinology 150: 3627-3636, 2009.

10. Davey HW, Park SH, Grattan DR, McLachlan MJ and Waxman DJ: STAT5b-deficient mice are growth hormone pulse-resistant. Role of STAT5b in sex-specific liver p450 expression. J Biol Chem 274: 35331-35336, 1999.

11. Rabkin R, Sun DF, Chen Y, Tan J and Schaefer F: Growth hormone resistance in uremia, a role for impaired JAK/STAT signaling. Pediatr Nephrol 20: 313-318, 2005. 
12. Woelfle J, Chia DJ and Rotwein P: Mechanisms of growth hormone $(\mathrm{GH})$ action. Identification of conserved Stat5 binding sites that mediate GH-induced insulin-like growth factor-I gene activation. J Biol Chem 278: 51261-51266, 2003.

13. Zhang R, Ruan D and Zhang C: Effects of TGF-beta1 and IGF-1 on proliferation of human nucleus pulposus cells in medium with different serum concentrations. J Orthop Surg Res 1: 9, 2006.

14. Weng CY, Kothary PC, Verkade AJ, Reed DM and Del Monte MA: MAP kinase pathway is involved in IGF-1-stimulated proliferation of human retinal pigment epithelial cells (hRPE). Curr Eye Res 34: 867-876, 2009.

15. King B, Jiang Y, Su X, Xu J, Xie L, Standard J and Wang W: Weight control, endocrine hormones and cancer prevention. Exp Biol Med 238: 502-508, 2013.

16. Tuncer PB, Bucak MN, Büyükleblebici S, Sarıözkan S, Yeni D Eken A, Akalın PP, Kinet H, Avdatek F, Fidan AF, Gündoğan M: The effect of cysteine and glutathione on sperm and oxidative stress parameters of post-thawed bull semen. Cryobiology 61 : 303-307, 2010.

17. Salman ZK, Refaat R, Selima E, El Sarha A and Ismail MA: The combined effect of metformin and L-cysteine on inflammation, oxidative stress and insulin resistance in streptozotocin-induced type 2 diabetes in rats. Eur J Pharmacol 714: 448-455, 2013.

18. Yang LJ, Wan R, Shen JQ, Shen J and Wang XP: Effect of L-cysteine on remote organ injury in rats with severe acute pancreatitis induced by bile-pancreatic duct obstruction. Hepatobiliary Pancreat Dis Int 12: 428-435, 2013.

19. Reeves PG, Nielsen FH and Fahey GC Jr: AIN-93 purified diets for laboratory rodents: final report of the American Institute of Nutrition ad hoc writing committee on the reformulation of the AIN-76A rodent diet. J Nutr 123: 1939-1951, 1993.

20. Farombi EO, Nwankwo JO and Emerole GO: The effect of modulation of glutathione levels on markers for aflatoxin B1-induced cell damage. Afr J Med Med Sci 34: 37-43, 2005.

21. Choi IY, Moon PD, Koo HN, Myung NY, Kim SJ, Lee JH, Han SH, Moon G, Seo SY and Sung HJ: Observations of Forsythia koreana methanol extract on mast cell-mediated allergic reactions in experimental models. In Vitro Cell Dev Biol Anim 43: 215-221, 2007.

22. Moon PD and Kim HM: Thymic stromal lymphopoietin is expressed and produced by caspase $-1 / \mathrm{NF}-\mathrm{\kappa B}$ pathway in mast cells. Cytokine 54: 239-243, 2011.

23. Moon PD and Kim HM: Suppression of thymic stromal lymphopoietin production by rutin in mast cells. Food Chem 133: 76-81, 2012.

24. Moon PD, Jeong HJ and Kim HM: Down-regulation of thymic stromal lymphopoietin by curcumin. Pharmacol Rep 65: 525-531, 2013.

25. Han NR, Kim HM and Jeong HJ: Kanamycin activates caspase-1 in NC/Nga mice. Exp Dermatol 20: 659-663, 2011.

26. Moon PD, Choi IH and Kim HM: Epigallocatechin-3-O-gallate inhibits the production of thymic stromal lymphopoietin by the blockade of caspase-1/NF- $\mathrm{B}$ pathway in mast cells. Amino Acids 42: 2513-2519, 2012a.

27. Moon PD, Jeong HJ, Kim SJ, An HJ, Lee HJ, Yang WM, Park SK, Hong SH, Kim HM and Um JY: Use of electroacupuncture at ST36 to inhibit anaphylactic and inflammatory reaction in mice. Neuroimmunomodulation 14: 24-31, 2007.

28. Moon PD and Kim HM: The suppression of thymic stromal lymphopoietin expression by selenium. Amino Acids 43 999-1004, 2012.

29. Moon PD, Jeong HJ and Kim HM: Effects of schizandrin on the expression of thymic stromal lymphopoietin in human mast cell line HMC-1. Life Sci 91: 384-388, 2012.

30. Moon PD and Kim HM: Antiinflammatory effects of traditional Korean medicine, JinPi-tang and its active ingredient, hesperidin in HaCaT cells. Phytother Res 26: 657-662, 2012.
31. Ngueguim FT, Khan MP, Donfack JH, Siddiqui JA, Tewari D, Nagar GK, Tiwari SC, Theophile D, Maurya R and Chattopadhyay N: Evaluation of Cameroonian plants towards experimental bone regeneration. J Ethnopharmacol 141: 331-337, 2012.

32. Sharan K, Mishra JS, Swarnkar G, Siddiqui JA, Khan K, Kumari R, Rawat P, Maurya R, Sanyal S and Chattopadhyay N: A novel quercetin analogue from a medicinal plant promotes peak bone mass achievement and bone healing after injury and exerts an anabolic effect on osteoporotic bone: the role of aryl hydrocarbon receptor as a mediator of osteogenic action. J Bone Miner Res 26: 2096-2111, 2011

33. Locatelli V and Bianchi VE: Effect of GH/IGF-1 on bone metabolism and osteoporsosis. Int J Endocrinol: Jul 23, 2014 doi 10.1155/2014/235060 (Epub ahead of print).

34. Lee SH, Kim JY, Kim H, Park SK, Kim CY, Chung SY and Chang GT: Amomum villosum induces longitudinal bone growth in adolescent female rats. J Tradit Chin Med 32: 453-458, 2012.

35. Suzuki Y, Suda K, Matsuyama Y, Era S and Soejima A: Close relationship between redox state of human serum albumin and serum cysteine levels in non-diabetic CKD patients with various degrees of renal function. Clin Nephrol 82: 320-325, 2014.

36. Bauchart-Thevret C, Stoll B, Chacko S and Burrin DG: Sulfur amino acid deficiency upregulates intestinal methionine cycle activity and suppresses epithelial growth in neonatal pigs. Am J Physiol Endocrinol Metab 296: E1239-1250, 2009.

37. McLean AE, Armstrong GR and Beales D: Effect of D- or L-methionine and cysteine on the growth inhibitory effects of feeding 1\% paracetamol to rats. Biochem Pharmacol 38: 347-352, 1989.

38. Bird SD, Legge $M$ and Walker RJ: L-cysteine improves growth of human peritoneal mesothelial cells in vitro. Perit Dial Int 16: 599-606, 1996.

39. Baines M, Kredan MB, Davison A, Higgins G, West C, Fraser WD and Ranganath LR: The association between cysteine, bone turnover, and low bone mass. Calcif Tissue Int 81: 450-454, 2007.

40. Schmeling H, Seliger E and Horneff G: Growth reconstitution in juvenile idiopathic arthritis treated with etanercept. Clin Exp Rheumatol 21: 779-784, 2003.

41. Marcovecchio ML, Mohn A and Chiarelli F: Inflammatory cytokines and growth in childhood. Curr Opin Endocrinol Diabetes Obes 19: 57-62, 2012.

42. Mehls O and Fine RN: Growth hormone treatment after renal transplantation: a promising but underused chance to improve growth. Pediatr Nephrol 28: 1-4, 2013.

43. Baron J, Huang Z, Oerter KE, Bacher JD and Cutler GB Jr: Dexamethasone acts locally to inhibit longitudinal bone growth in rabbits. Am J Physiol 263: E489-E492, 1992.

44. Chrysis D, Zaman F, Chagin AS, Takigawa M and Sävendahl L: Dexamethasone induces apoptosis in proliferative chondrocytes through activation of caspases and suppression of the Akt-phosphatidylinositol 3'-kinase signaling pathway. Endocrinology 146: 1391-1397, 2005.

45. Argetsinger LS and Carter-Su C: Mechanism of signaling by growth hormone receptor. Physiol Rev 76: 1089-1107, 1996.

46. Sandoval-Usme MC, Umaña-Pérez A, Guerra B, Hernández-Perera O, García-Castellano JM, Fernández-Pérez L and Sánchez-Gómez M: Simvastatin impairs growth hormone-activated signal transducer and activator of transcription (STAT) signaling pathway in UMR-106 osteosarcoma cells. PLoS One 9: e87769, 2014 